\title{
Yolk sac tumor of upper lip: A case report
}

\author{
ZHANWEI CHEN, PEIHUI ZHENG, \\ SHENGYUN HUANG and DONGSHENG ZHANG
}

\begin{abstract}
Department of Oral and Maxillofacial Surgery, Shandong Provincial Hospital Affiliated to Shandong University, Jinan, Shandong 250000, P.R. China
\end{abstract}

Received April 1, 2016; Accepted September 2, 2017

DOI: $10.3892 / \mathrm{ol} .2017 .6918$

\begin{abstract}
Yolk sac tumors (YSTs) are a type of malignant germ cell tumor that usually grow in the gonads. They are difficult to recognize at other sites outside the gonads, and no case has been reported involving the upper lip. The present study reported the case of a 13-month-old girl exhibiting an isolated YST occurring in the upper lip. The histology and elevation of $\alpha$-fetoprotein were typical for a YST. The patient was cured following effective chemotherapy and surgery resection. After 36 months of follow-up, there was no sign of recurrence or metastasis. A total of 20 cases of primary YSTs of the head and neck extracranial region since 1997 were reviewed. The present study aims to inform the scientific community of the clinical and pathologic features of this patient.
\end{abstract}

\section{Introduction}

Yolk sac tumors (YSTs), also referred to as endodermal sinus tumors, are a type of malignant germ cell tumor that usually grow in the gonads (1). In 1959, the tumor was identified in the ovaries and testes of young patients, and defined as a specific form of malignant germ cell neoplasm by Telium (2). YSTs are difficult to identify in other sites outside the gonads. However, between 10 and $15 \%$ of YST occur in the midline structures of the mediastinum, retroperitoneum and sacrococcygeal areas (3). Certain cases have been reported in other location such as in the pineal region and head and neck $(4,5)$. No case has been reported involving the upper lip. The present study reports the case of a child with an isolated YST occurring in the upper lip, and reviews 20 cases of primary YST of the head and neck region, not including the intracranial and orbit regions, from the literature since 1997.

Correspondence to: Professor Dongsheng Zhang, Department of Oral and Maxillofacial Surgery, Shandong Provincial Hospital Affiliated to Shandong University, 324 Jingwu Road, Lixia, Jinan, Shandong 250000, P.R. China

E-mail: ds63zhang@sdu.edu.cn

Key words: yolk sac tumor, upper lip, endodermal sinus tumor, germ cell tumor

\section{Case report}

A 13-month-old female damaged her upper lip upon falling and the hematoma formed 2 months prior to admission to hospital. The patient underwent a hematoma puncture drainage at Juxian People's Hospital (Rizhao, Cina), but the mass recurred quickly. Upon examination, an exogenous reddish mass measuring $4 \times 5 \mathrm{~cm}$ in diameter was revealed at the midline of the upper lip. The surface of the tumor was bleeding and scabby, as demonstrated in Fig. 1. Magnetic resonance imaging demonstrated a strong signal mass on the fat suppression imaging T2 weighted image in the upper lip with a clear border, as illustrated in Fig. 2. A biopsy sample was obtained from the fleshy mass under general anesthesia and the results confirmed the diagnosis of a YST. The biopsy sample was cut into pathological sections (4 $\mu \mathrm{m}$ thick). Certain pathological sections underwent hematoxylin-eosin staining (stained with hematoxylin-eosin at $60^{\circ} \mathrm{C}$ for $60 \mathrm{sec}$ ) and others underwent immunohistochemical staining with $\alpha$-fetoprotein (incubated with anti- $\alpha$-fetoprotein at $37^{\circ} \mathrm{C}$ for $2 \mathrm{~h}$ ). Subsequently, the tissue sections were observed using a biological microscope at a magnification of $\mathrm{x} 400$. Microscopic analysis revealed the characteristic reticular pattern and eosinophilic ball, as demonstrated in Fig. 3, Schiller-Duval bodies, as illustrated in Fig. 4, and immunohistochemical staining positive for $\alpha$-fetoprotein (AFP), as demonstrated in Fig. 5. Laboratory screening revealed an AFP level $>1,308 \mu \mathrm{g} / 1$, with $1-30 \mu \mathrm{g} / \mathrm{l}$ being the normal range. Computerized tomography scans of the head, neck and thoracic regions and ultrasonography of the abdominal and pelvic areas demonstrated no signs of metastasis. Initial treatment comprised two cycles of Adriamycin $\left(30 \mathrm{mg} / \mathrm{m}^{2}\right.$, day 2,9$)$, vincristine $\left(1.5 \mathrm{mg} / \mathrm{m}^{2}\right.$, day 1,8$)$, cyclophosphamide $\left(300 \mathrm{mg} / \mathrm{m}^{2}\right.$, day $\left.1-3\right)$ and cisplatin $\left(90 \mathrm{mg} / \mathrm{m}^{2}\right.$, day 1$)$ (AVCP) chemotherapy and 1 cycle of ifosfamide $\left(1.5 \mathrm{~g} / \mathrm{m}^{2}\right.$, day $1-5)$, etoposide $\left(100 \mathrm{mg} / \mathrm{m}^{2}\right.$, day $\left.1-5\right)$ and vincristine $\left(1.5 \mathrm{mg} / \mathrm{m}^{2}\right.$, day 1,8$)(\mathrm{IEV})$ chemotherapy. Subsequent to this regimen, the mass in the upper lip reduced to $\sim 1 \times 2 \mathrm{~cm}$ in diameter. The patient then underwent surgical resection. The biopsies of the resected area revealed only fibrosis, without any residual tumor tissue. The AFP level was measured subsequent to chemotherapy and resection, and exhibited a decline to within the normal range. After 36 months, there were no signs of recurrence or metastasis at follow-up examination. 


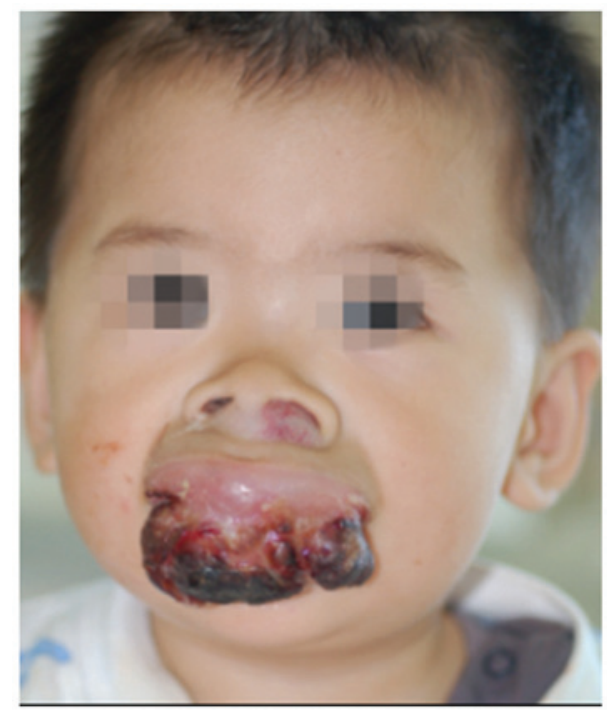

Figure 1. Yolk sac tumor in the upper lip of the patient.

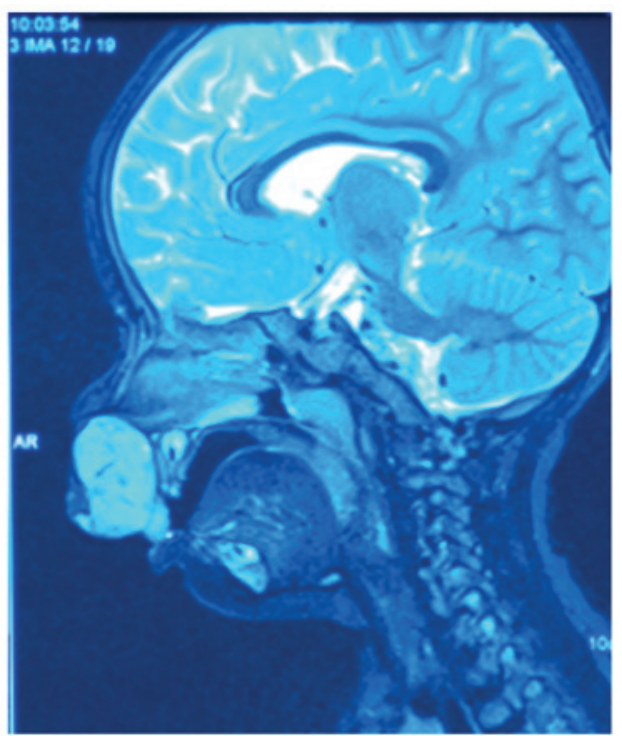

Figure 2. Magnetic resonance imaging demonstrated a strong signal mass on the sagittal section of the fat suppression T2 image in the upper lip with a clear border.

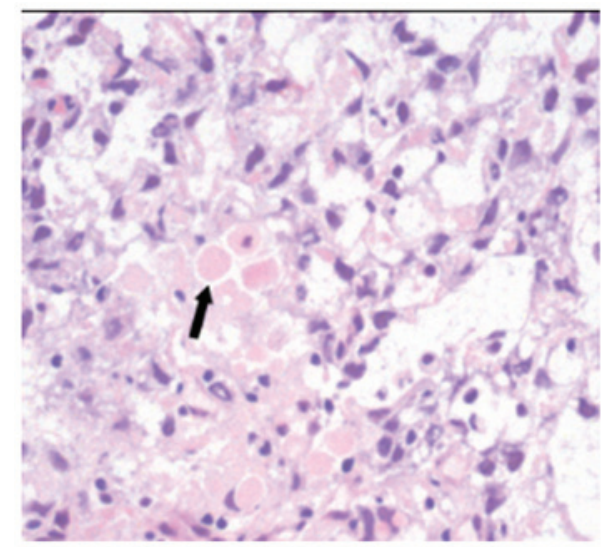

Figure 3. Characteristic reticular pattern and arrow highlights the eosinophilic balls of the hematoxylin-eosin stained tumor cells, at magnification, x400 using an Olympus CX23 microscope.

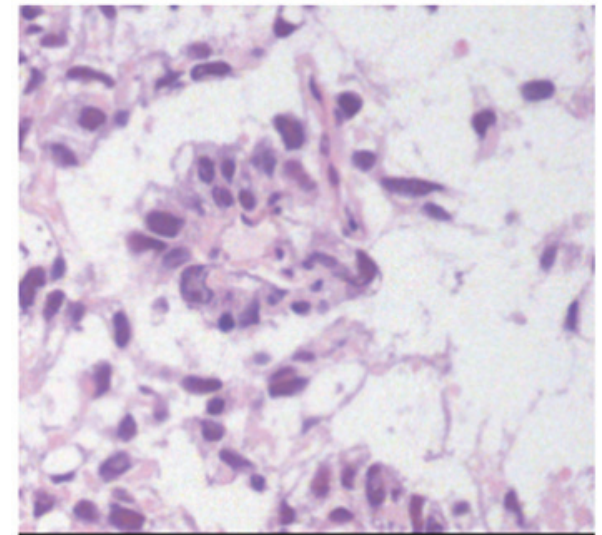

Figure 4. Cuboidal or low columnar-shaped tumor cells around the blood vessels forming characteristic Schiller-Duval body. Hematoxylin-eosin staining, at magnification, x400 using an Olympus CX23 microscope.

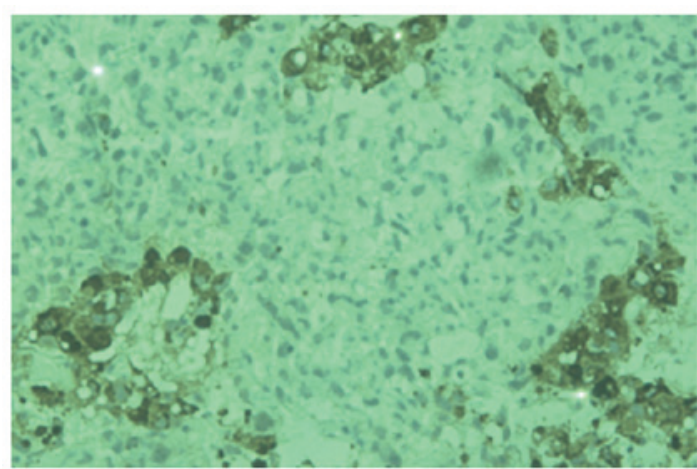

Figure 5. Immunohistochemical staining was positive for $\alpha$-fetoprotein, at magnification, x400 using an Olympus CX23 microscope.

\section{Discussion}

YSTs are one of the most common types of malignant germ cell tumor exhibited within the pediatric age group, particularly in females $(4,6)$. To the best of our knowledge, few cases of YST in the head and neck have been reported, whilst no cases have been reported involving the upper lip. Devaney and Ferlito (5) reviewed 27 patients with primary YSTs of the head and neck extracranial regions prior to 1997 , and Kamal et al (7) reviewed 16 patients with primary orbital YST, yet there has been no review of those cases subsequent to 1997 . Therefore, the present study reviewed 20 patients with primary YST of the head and neck region, not including intracranial and orbit region, occurring subsequent to 1997, and discussed the clinical and pathological features of YSTs, as summarized in Table I.

The mechanisms underlying primitive yolk sac cell migration to the upper lip remain unknown. There are two principal theories that have been put forward to explain the origin of extragonadal germ cell tumors (EGCTs) (8). The first hypothesizes that during embryonic development, those EGCTs arising from primordial germ cells are caused by defects in the cell migration pathways. In the 4-week-old embryo, primordial germ cells first appear in the wall of the yolk sac and migrate along the dorsal mesentery to the genital ridge during embryogenesis (9). Certain germ cells may not complete this 


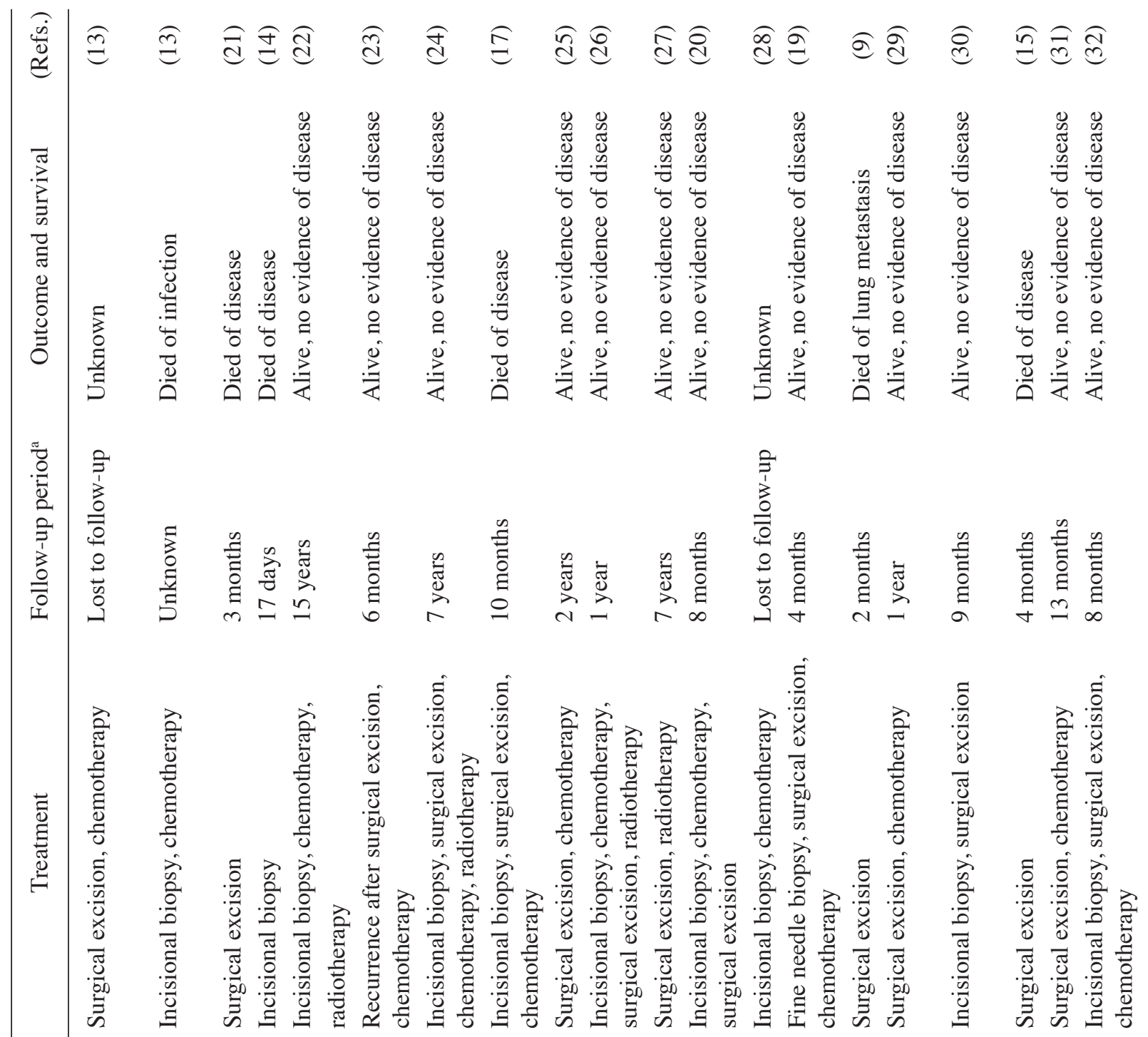

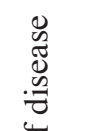

若

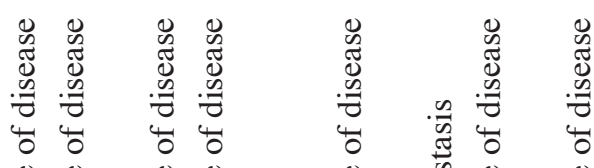

(4)

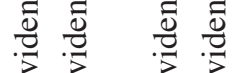

.

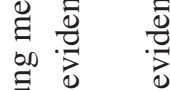

สิ

:

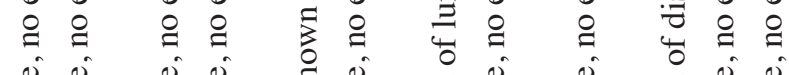

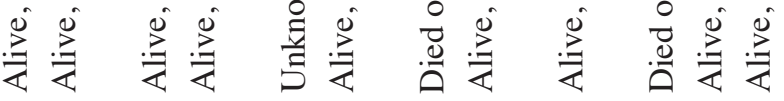

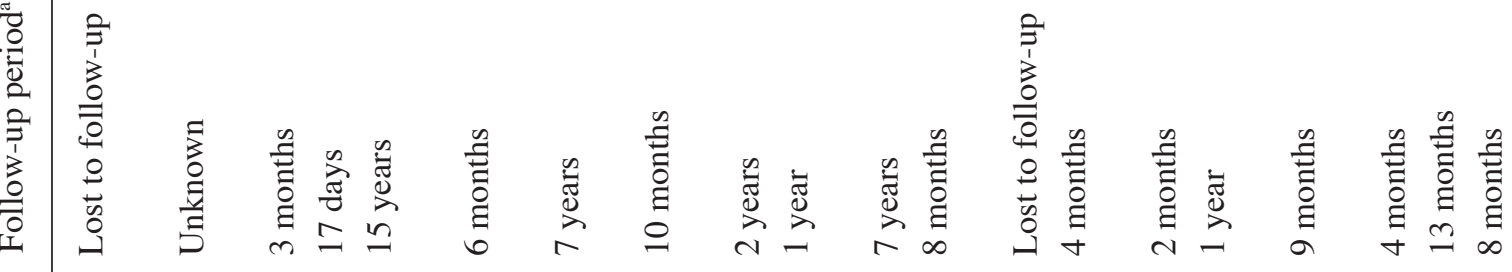
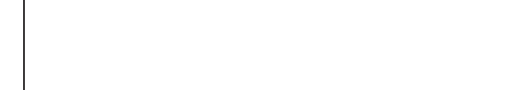
migration, resulting in retention at several sites along the dorsal wall of the embryo near the midline (9). This provides the basis for the midline propensity of the case reported in the present study, but does not explain the development of EGCTs in the out-of-midline regions. The second theory suggests that EGCTs arise from totipotential cells, which are scattered throughout numerous areas of the body during embryonic development and normally remain dormant. However, these cells possess the potential for additional growth and differentiation when suitably stimulated, leading to the formation of EGCTs (8).

In the rare case discussed in the present study the diagnosis was established by histological and immunohistochemical examinations. The major pathologic characteristics of YSTs include a reticular pattern, a solid pattern, a hepatoid pattern with hyaline globules, a festoon pattern, enteric differentiation, Schiller-Duval bodies, the presence of a granulomatous tissue reaction and a polyvesicular vitelline pattern $(10,11)$. Schiller-Duval bodies have been reported as a common feature to extragonadal YSTs, as observed in large quantities in a previous study (12). Typical Schiller-Duval bodies comprise cuboidal or low columnar-shaped tumor cells surrounding the capillaries of a thin-walled sinus $(13,14)$. Immunohistochemically, AFP is an important tumor biomarker for diagnosis (15). Immunofluorescent techniques have been developed to localize the site of AFP synthesis in YST samples (16). The serum level of AFP was elevated in the patient of the present study, and reduced subsequent to excision of the tumor. The serum levels of the protein may be used as a tumor biomarker during diagnosis, and in the follow-up of patients with YST $(14,17)$.

Similar to testicular tumors, YSTs generally exhibit a poor prognosis as they tend to recur locally and demonstrate a high incidence of metastasis (18). Consequently, therapy includes extensive surgical resection, an intensive combination of chemotherapies and occasionally radiation therapy (19). Chemotherapy may improve the prognosis between 20-50\% for YSTs (18). The combination of cisplatin, bleomycin and etoposide has been demonstrated to be effective, and is the most common type of chemotherapeutic regimen (4). The patient of the present study was administered AVCP chemotherapy. When the first cycle of AVCP chemotherapy was completed, the patient exhibited bone marrow suppression associated with an infection and high fever. Consequently, treatment was altered temporarily to IEV chemotherapy. Subsequent to 3 cycles of chemotherapy, the tumor mass of our case almost entirely disappeared and the patient was eligible for surgical resection All cases of YST should receive adjuvant chemotherapy except primary testicular tumors, which exhibit excellent responses to surgery alone (20).

The present study reported the first case of an isolated YST in the upper lip. The histology and AFP elevation were typical for this tumor. In the case of the present study, the YST was cured through effective chemotherapy and surgical resection. The patient remained asymptomatic after 36 months and exhibited no sign of recurrence or metastasis. According to data of previous studies, multimodal therapy including surgery, chemotherapy and radiotherapy may achieve a good prognosis.

\section{References}

1. Brodeur GM, Howarth CB, Pratt CB, Caces J and Hustu HO: Malignant germ cell tumors in 57 children and adolescents. Cancer 48: 1890-1898, 1981.

2. Telium G: Endodermal sinus tumors of the ovary and testes. Comparative morphogenesis of the so-called mesonephroma ovarii (Schiller) and extraembryonic (yolk sac-allantoic) structures of the rat's placenta. Cancer 12: 1092-1105, 1959.

3. Shebib S, Sabbah RS, Sackey K, Akhtar M and Aur RJ: Endodermal sinus (yolk sac) tumor in infants and children. A clinical and pathological study: An 11 year review. Am J Pediatr Hematol Oncol 11: 36-39, 1989.

4. Devaney KO, Perlito A and Rinaldo A: Endodermal sinus tumor (yolk sac tumor) of the temporal bone: An exotic disease for otorhinolaryngologists and head and neck surgeons. Acta Otolaryngol 123: 747-748, 2003.

5. Devaney KO and Ferlito A: Yolk sac tumors (endodermal sinus tumors) of the extracranial head and neck regions. Ann Otol Rhinol Laryngol 106: 254-260, 1997.

6. Harms D and Jänig U: Germ cell tumours of childhood. Report of 170 cases including 59 pure and partial yolk-sac tumours. Virchows Arch A Pathol Anat Histopathol 409: 223-239, 1986.

7. Kamal S, Kaliki S, Sreedhar A and Mishra DK: Primary orbital yolk sac tumor: Report of a case and review of literature. Int Ophthalmol 36: 435-444, 2016

8. Brown NJ: Teratomas and yolk-sac tumors. J Clin Pathol 29: 1021-1025, 1976

9. Jin $\mathrm{X}$, Han $\mathrm{C}$ and Sun H: Primary yolk sac tumor in floor of mouth in a child. J Oral Maxillofac Surg 69: 1973-1977, 2011.

10. Narita T, Moriyama Y and Ito Y: Endodermal sinus (yolk sac) tumor of the liver. A case report and review of the literature. J Pathol 155: 41-47, 1988.

11. Robban JT and Zaloudek C: Ovarian yolk sac tumors. Pathol Case Rev 11: 50-57, 2006.

12. Juckes AW, Fraser MM and Detxer D: Endodermal sinus (yolk sac) tumors in infants and children. J Pediatr Surg 14: 520-524, 1979.

13. Kusumakumari P, Geetha N, Chellam VG and Nair MK: Endodermal sinus tumors in the head and neck region. Med Pediatr Oncol 29: 303-307, 1997.

14. Kutluhan A, Uğraş S and Akman E: Endodermal sinus (yolk sac) tumor of oral cavity originating from gingiva. Auris Nasus Larynx 25: 459-462, 1998.

15. Zhang Q, Huang Y, Bao CY and Li LJ: Yolk sac tumour involving floor of mouth: Case report. Br J Oral Maxillofac Surg 51: e67-e69, 2013.

16. Wold LE, Kramer SA and Farrow GM: Testicular yolk sac and embryonal carcinomas in pediatric patients: Comparative immunohistochemical and clinicopathologic study. Am J Clin Pathol 81: 427-435, 1984.

17. Westerveld GJ, Quak JJ, Bresters D, Zwaan CM, van der Valk P and Leemans CR: Endodermal sinus tumor of the maxillary sinus. Otolaryngol Head Neck Surg 124: 691-692, 2001.

18. Ablin AR, Krailo MD, Ramsay NK, Malogolowkin MH, Isaacs H, Raney RB, Adkins J, Hays DM, Benjamin DR, Grosfeld JL, et al: Results of treatment of malignant germ cell tumors in 93 children: A report from the Children's Cancer Study Group. J Clin Oncol 9: 1782-1792, 1991.

19. Furtado LV, Leventaki V, Layfield LJ, Lowichik A, Muntz HR and Pysher TJ: Yolk sac tumor of the thyroid gland: A case report. Pediatr Dev Pathol 14: 475-479, 2011.

20. Steinbacher DM, Upton J, Rahbar R and Ferraro NF: Yolk sac tumor of the mandible. J Oral Maxillofac Surg 66: 151-153, 2008.

21. Choufani G, Saussez S, Detemmerman D, Salmon I, Tainmont J, Louryan S, Remmelink M and Hassid S: Yolk sac tumor of the ear in a child. Am J Otol 19: 298-300, 1998.

22. Gangopadhyay K, McArthur PD, Martin JM and Saleem M: Endodermal sinus tumor of the maxillary sinus: A case report. Ear Nose Throat J 78: 376-377, 381-382, 1999.

23. Frank TC, Anand VK and Subramony C: Yolk sac tumor of the temporal bone: Report of a case. Ear Nose Throat J 79: 183, 187-188, 191-192, 2000.

24. Gábris K, Orosz M and Suba Z: The effects on teeth of radiotherapy for nasal endodermal sinus tumor (yolk sac tumor) in childhood. Int J Oral Maxillofac Surg 30: 356-358, 2001.

25. Sredni ST, da Cunha IW, de Carvalho Filho NP, Magrin J, Pinto CA and Lopes LF: Endodermal sinus tumor of the parotid gland in a child. Pediatr Dev Pathol 7: 77-80, 2004. 
26. Mishra A, El-Naggar AK, DeMonte F and Hanna EY: Endodermal sinus tumor of the paranasal sinuses. Head Neck 30: 539-543, 2008

27. Filho BC, McHugh JB, Carrau RL and Kassam AB: Yolk sac tumor in the nasal cavity. Am J Otolaryngol 29: 250-254, 2008.

28. Pasricha S, Gupta A, Shah M and Vadodaria H: Extragonadal yolk sac tumor of face in a female infant: A case report. Indian J Pathol Microbiol 53: 592-593, 2010.

29. Mamoon N, Jaffri SA, Ilahi F, Muzaffar K, Iqbal Y, Akhter N, Nasir H and Ahmad IN: Yolk sac tumour arising in mature teratoma in the parapharyngeal space. J Pak Med Assoc 61: 1025-1027, 2011.
30. Rozbahany NA, Hasanzadazar M, Latifi H, Mohammadi A, Ilkhanizadeh B and Ghasemi-Rad M: Yolk-sac tumor of the postauricular region: Case report and review of the literature. J Oral Maxillofac Surg 70: 1891-1895, 2012.

31. Chuang HC, Kang CJ and Lee LY: Sinonasal pure yolk sac tumor: A case report and literature review. Fetal Pediatr Pathol 33: 127-134, 2014.

32. Mei X, Xia Y, Sasano H and Gao H: Sinonasal yolk sac (Endodermal sinus) tumor in an adult female-A case report and review of the literature. APMIS 123: 810-814, 2015. 